\title{
Clinical Course of Pediatric Acute Respiratory Distress Syndrome at Moderate Altitude
}

\author{
María A. Chacón $^{1}$, Alejandra Calderon ${ }^{2}$, Jaime Fernández-Sarmiento ${ }^{3}$, Blanca Rios ${ }^{3}$ \\ 1. Pediatric Critical Care, Universidad de La Sabana, Bogotá, COL 2. Pediatric Oncology, Instituto Nacional de \\ Cancerologia, Bogotá, COL 3. Pediatric Critical Care, Fundación Cardioinfantil Instituto de Cardiología, Bogotá, COL
}

Corresponding author: Alejandra Calderon, calderongasca@gmail.com

\section{Abstract \\ Background}

This is a retrospective case series, and the main objective is to describe the epidemiology, clinical features, and outcomes of pediatric acute respiratory distress syndrome in patients at moderate altitude.

\section{Methods}

Children from the Pediatric Intensive Care Unit (PICU) at the Fundación Cardioinfantil, hospitalized with acute respiratory distress syndrome, were prospectively enrolled from March 2009 to March 2014. We evaluated the demographic data, mechanical ventilation, gas exchange, hemodynamics, and multiorgan dysfunction.

\section{Results}

During the study period, 88 patients met the inclusion criteria. Bronchiolitis and pneumonia were the most common causes of acute respiratory distress syndrome. The overall mortality rate was $19.5 \%$. At the beginning of the study, the average relation between blood pressure and the fraction of inspired oxygen $(\mathrm{Pa} / \mathrm{Fi})$ was $130.3 \pm 52.2$; tidal volume was $7.94 \pm 1.7 \mathrm{ml} / \mathrm{kg}$, the plateau pressure $25.3 \pm 5.09 \mathrm{cmH}_{2} \mathrm{O}$, and positive end-expiratory pressure was $7.2 \pm 3.2 \mathrm{cmH}_{2} \mathrm{O}$. After 24 hours, the mortality rate in the group with severe acute respiratory distress syndrome $(\mathrm{Pa} / \mathrm{Fi}<100)$ was $46.7 \%$, in the moderate acute respiratory distress syndrome group ( $\mathrm{Pa} / \mathrm{Fi} 100-200)$ it was $11.9 \%$, and finally in the mild acute respiratory distress syndrome group ( $\mathrm{Pa} / \mathrm{Fi} 200-300)$ the mortality was $25 \%$. This study found a relation between serum lactate value and positive end-expiratory pressure and mortality $(p=0.02$ and 0.0013$)$.

\section{Conclusions}

This study shows that pediatric acute respiratory distress syndrome patients at moderate altitudes have similar clinical behavior, including mortality rate, to those at low altitudes. However, $\mathrm{Pa} / \mathrm{Fi}$ is not a good predictor of mortality for patients with mild and moderate acute respiratory distress syndrome.

Received 08/28/2020

Review began 09/05/2020 Review ended 09/24/2020 Published 09/25/2020

\section{() Copyright 2020}

Chacón et al. This is an open access article distributed under the terms of the Creative Commons Attribution License CC-BY 4.0., which permits unrestricted use, distribution, and reproduction in any medium, provided the original author and source are credited.
Categories: Pediatrics, Pulmonology, Other

Keywords: acute respiratory distress syndrome, children, protective ventilation, moderate altitude

\section{Introduction}

Acute respiratory distress syndrome (ARDS) is characterized by injury of the alveolar-capillary membrane leading to pulmonary edema, decreased pulmonary compliance, and increased shunt, causing an impaired oxygenation/ventilation and respiratory failure [1].

ARDS was first described in 1967 by Dr. Ashbaug in a case series of 12 patients with tachypnea, cyanosis, severe dyspnea refractory to oxygen, loss of pulmonary compliance, and patchy alveolar infiltrates on chest x-ray [2]. Later in 1994, the American European Consensus established the main components of the definition including chest $\mathrm{x}$-ray and the relation between blood pressure and fraction of inspired oxygen ( $\mathrm{Pa} / \mathrm{Fi}$ ), and according to those parameters categorized acute lung injury and ARDS [3].

Using a consensus process, a panel of experts convened in 2011 (an initiative of the European Society of Intensive Care Medicine endorsed by the American Thoracic Society and the Society of Critical Care Medicine) developed the Berlin Definition. With new components of the definition of ARDS including the positive end-expiratory pressure (PEEP), timing, and chest radiograph findings, they proposed three mutually exclusive categories of ARDS based on the degree of hypoxemia: mild (200 mmHg $<\mathrm{Pa} / \mathrm{Fi} \leqslant 300$ $\mathrm{mmHg})$, moderate $(100 \mathrm{mmHg}<\mathrm{Pa} / \mathrm{Fi} \leqslant 200 \mathrm{mmHg})$, and severe $(\mathrm{Pa} / \mathrm{Fi} \leqslant 100 \mathrm{mmHg})$ [4].

The ARDS criteria have been described in the adult population with extrapolation of data to pediatric 
patients. Currently, there are few studies about epidemiology and mortality in children $[1,4,5]$.

Lopez et al. reported an overall mortality rate of $28 \%$ in pediatric patients; however, the mortality rate may change according to the $\mathrm{Pa} / \mathrm{Fi}$, (38\% in severe ARDS and 11\% in moderate ARDS), and he described a linear relationship between the number of impaired organs and mortality - when more than three organs are impaired the mortality increases to $70 \%[5]$.

Recent research has established the ARDS natural history in patients living below 1,000 metres above mean sea level (MAMSL) [5]. However, there are no clinical studies about ARDS natural history or mortality in cities above this level [6,7]. As the altitude increases, the availability of oxygen decreases, which is why humans have developed adaptive mechanisms to avoid hypoxemia [6,7]. Mild or moderate increases of altitude above 3000 meters are associated with important changes in oxygen saturation and pulmonary artery pressure. Altitude induces adaptive changes to the decrease in alveolar oxygen pressure [8].

The cardiovascular response is one of them; the hypoxia produces an initial increase in cardiac output by $22 \%$ and the heart rate by $18 \%$, maintaining a constant systolic volume. Then the cardiac output returns to the standard value with a decrease in systolic volume and persistence of high heart rate. Additionally, there is a decrease in maximum oxygen uptake to maintain homeostasis. Another component of the cardiovascular response is activation of the sympathetic nervous system in response to hypoxia; studies show an increase in catecholamine levels in the blood and urine of these patients, causing the high heart rate and hemodynamic changes described [9].

After two weeks of exposure to hypoxemia, hemoglobin synthesis is increased and, therefore, the blood viscosity, which results in decreased cardiac output, in theory; however, studies using isovolumetric hemodilution do not increase peripheral oxygen uptake and only increase cardiac output slightly [9].

We believe it is essential to analyze the disease's clinical behavior and establish the outcome in children with ARDS who have developed physiological mechanisms of adaptation to living at moderate and high altitudes.

This research was conducted to determine the natural history and etiology of ARDS in the pediatric population in Bogotá, located 2,630 meters above mean sea level (moderate altitude) [10].

\section{Materials And Methods}

\section{Study design and patients}

This observational retrospective case series was approved by the ethics committee of the Fundación Cardioinfantil Instituto de Cardiologia. It was not necessary to sign informed consent by parents because no intervention was performed on patients, and data was collected from the medical history.

During a period of five years (March 2009 to March 2014), patients aged from one month to 18 years admitted to the pediatric intensive care unit (PICU) of the Fundación Cardioinfantil Instituto de Cardiologia, who met the inclusion criteria based on the consensus of Berlin [2] were included in this study: respiratory symptoms within one week of a known clinical insult or new or worsening, chest x-ray with bilateral opacities not fully explained by effusions, lobar/lung collapse or nodules, edema not fully explained by cardiac failure or fluid overload, $\mathrm{Pa} / \mathrm{Fi} \leqslant 300 \mathrm{mmHg}$.

Exclusion criteria were: patients under one month and over 18 years, patients with congenital heart disease, and patients with cardiogenic pulmonary edema.

\section{Data collection and quality control}

In the beginning, data was collected from all patients admitted to the PICU at the Fundación Cardioinfantil from March 2009 to March 2014, whose admission diagnoses were pneumonia, bronchiolitis, respiratory failure, and septic shock. After this initial screening, these medical records were reviewed, and the inclusion and exclusion criteria were applied. Data were included in the study through a data collection instrument (Figure 1).

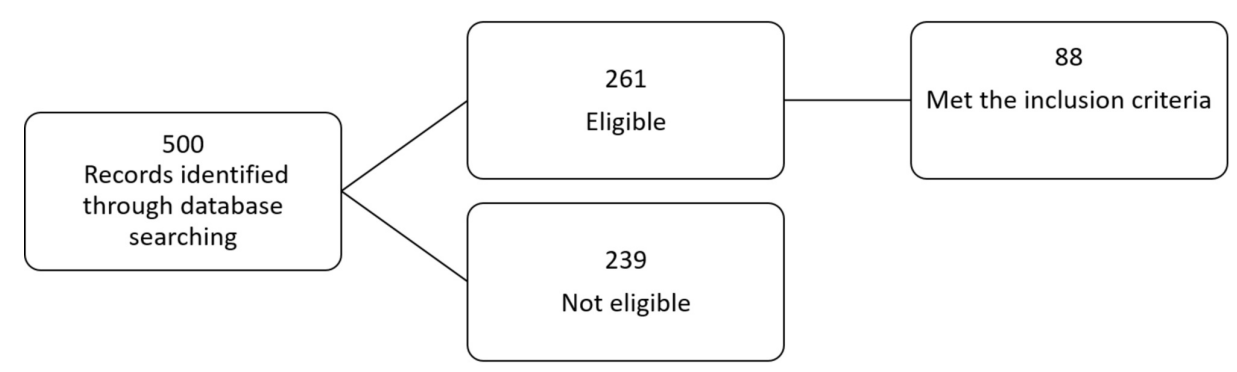


The onset of ARDS was defined as when the patient met the inclusion criteria set forth above. Demographic data, hemodynamic, pediatric index of mortality (PIM 2), arterial blood gases, ventilatory parameters and modes, chest x-ray, serum lactate, hemoglobin, and comorbidities were included (pneumothorax, shock septic, and multiorgan failure).

Plasma lactate values, hemodynamic data, ventilator settings, arterial blood gases, and hemoglobin were analyzed at the time of the ARDS diagnosis, at 24 hours, day three, day seven, and the last day of mechanical ventilation.

The relation between $\mathrm{Pa} / \mathrm{Fi}$ and PEEP levels of more than $5 \mathrm{cmH}_{2} \mathrm{O}$ for classifying ARDS in mild, moderate, and severe was used: mild (200 $\mathrm{mmHg}<\mathrm{Pa} / \mathrm{Fi} \leqslant 300 \mathrm{mmHg}$ ), moderate (100 mmHg < Pa/Fi $\leqslant 200 \mathrm{mmHg}$ ), and severe $(\mathrm{Pa} / \mathrm{Fi} \leqslant 100 \mathrm{mmHg})$. $\mathrm{Pa} / \mathrm{Fi}$ ratio, septic shock, multiple organ dysfunction, and pneumothorax were also evaluated.

The ventilation parameters tidal volume in $\mathrm{ml} / \mathrm{kg}$, PEEP, and plateau pressure were analyzed; in highfrequency ventilation, the parameters mean airway pressure, amplitude, respiratory rate, and the fraction of inspired oxygen $\left(\mathrm{FIO}_{2}\right)$ were analyzed. Ventilation modes were also identified. Total days of mechanical ventilation, length of hospital stay, and mortality rate were analyzed.

\section{Statistic analysis}

Absolute and relative frequencies for categorical variables, and the median and interquartile range for quantitative variables before assessing the normality assumption based on the Shapiro Wilks was obtained. The correlation between mortality and severity, the number of involved organs, tidal volume, PEEP, and serum lactate was made by Spearman's Rank Correlation Coefficient.

The comparison between the medians of the variables tidal volume, PEEP, and serum lactate at 24 hours and last day of mechanical ventilation between the group of patients who died and those who did not, was done using the Mann-Whitney U test. All statistical analyses were performed using a standard software package (Stata version 12; StataCorp., College Station, TX, USA).

\section{Results}

During the study, 500 medical records were reviewed, and 261 of them were eligible because of the diagnosis at the admission of shock, ventilatory failure, pneumonia, or bronchiolitis. Only 88 patients met the inclusion criteria (Figure 1). The median age was one year, and 59.8\% were men. The leading cause of ARDS was pneumonia in $78.1 \%$, followed by bronchiolitis in $9.1 \%$ and sepsis in third place. Septic shock was present in $97.7 \%$ of cases. The overall mortality rate was $19.5 \%$, and the Pediatric Mortality Index 2 at admission was $2 \pm 1.3$; the last one was used as a severity score (Table 1). 


\section{Cureus}

\begin{tabular}{|c|c|c|c|c|c|c|c|}
\hline Parameter & $\mathbf{n}$ & $\%$ & Median & Min & Max & Mean & SD \\
\hline Age (years) & & & 1 & 0.4 & 4 & & \\
\hline \multicolumn{8}{|l|}{ Sex } \\
\hline Male & 156 & 59.8 & & & & & \\
\hline Female & 105 & 40.2 & & & & & \\
\hline Length of stay in PICU (days) & & & 15 & 10 & 23 & & \\
\hline Mechanical ventilation days & & & 8 & 6 & 14 & & \\
\hline $\mathrm{Pa} / \mathrm{Fi}$ at admission & & & & & & 130.3 & 52.2 \\
\hline Tidal volume $(\mathrm{ml} / \mathrm{kg})$ Onset of ARDS & & & & & & 7.94 & 1.7 \\
\hline Plateau pressure $\left(\mathrm{cmH}_{2} \mathrm{O}\right)$ Onset ARDS & & & & & & 25.3 & 5.09 \\
\hline PEEP $\left(\mathrm{cmH}_{2} \mathrm{O}\right)$ Onset ARDS & & & & & & 7.2 & 3.2 \\
\hline Neumothorax & 5 & 5.7 & & & & & \\
\hline Septic shock & 85 & 97.7 & & & & & \\
\hline Multiorgan dysfunction & 71 & 81 & & & & & \\
\hline \multicolumn{8}{|l|}{ Number of organs involved } \\
\hline Kidney - Heart- Lung- Hematologic & 22 & 25 & & & & & \\
\hline Kidney-Heart- Lung & 32 & 36.7 & & & & & \\
\hline Heart- Lung & 17 & 19.5 & & & & & \\
\hline Mortality & 17 & 19.5 & & & & & \\
\hline Pediatric Index of Mortality (PIM2) score 2 & & & & & & 2 & 1.3 \\
\hline \multicolumn{8}{|l|}{ Causes of ARDS } \\
\hline Pneumonia & 68 & 78.1 & & & & & \\
\hline Bronchiolitis & 8 & 9.1 & & & & & \\
\hline Sepsis & 7 & 8 & & & & & \\
\hline Others & 17 & 4.8 & & & & & \\
\hline
\end{tabular}

\section{TABLE 1: Demographic characteristics of patients and clinical details at diagnosis of ARDS.}

Max: Maximum; Min: Minimum; n: Number of assessed children; SD: Standard deviation.

ARDS: Acute Respiratory Distress Syndrome, PEEP: Positive End-Expiratory Pressure, Pa/Fi: Relation between blood pressure and the fraction of inspired oxygen, PIM2: Pediatric Index of Mortality score 2

The most common ventilation modes used at the beginning of ARDS were control pressure in $58.6 \%$ of the cases, followed by pressure regulated volume control in $21.8 \%$ of the cases. Weaning from mechanical ventilation was performed using Duopap in $24.1 \%$ of the cases, followed by Synchronized Intermittent Mandatory Ventilation (SIMV) mode with Pressure Support Ventilation (PSV) in $13.7 \%$ of the cases.

High-frequency ventilation was used as the initial ventilatory mode in three patients (3.4\%), and it was used for 16 patients (18.3\%) over the development of ARDS.

At the diagnosis of ARDS, the tidal volume was $7.9 \mathrm{ml} / \mathrm{kg} \pm 1.7 \mathrm{ml} / \mathrm{kg}$, the median was maintained between 7 $\mathrm{ml} / \mathrm{kg}$ and $8 \mathrm{ml} / \mathrm{kg}$ throughout the study. The plateau pressure baseline was $25.3 \pm 5.09 \mathrm{cmH}_{2} \mathrm{O}$ and varied from $15 \mathrm{cmH}_{2} \mathrm{O}$ to $26 \mathrm{cmH}_{2} \mathrm{O}$. PEEP was $7.2 \mathrm{cmH}_{2} \mathrm{O} \pm 3.2 \mathrm{cmH}_{2} \mathrm{O}$, and the median was maintained between 6 $\mathrm{cmH}_{2} \mathrm{O}$ and $6.5 \mathrm{cmH}_{2} \mathrm{O}$. That was the lung-protective ventilation strategy used in the study. A detailed description of the ventilatory gas exchange variables throughout the study is reported in Table 2 . 


\section{Cureus}

\begin{tabular}{|llllll|}
\hline Variable & Diagnosis & 24 hours & Day 3 & Day 7 & Last day of mechanical ventilation \\
\hline Tidal volume $(\mathrm{ml} / \mathrm{kg})$ & $7.90 \pm 1.75$ & $10.4 \pm 1.43$ & $10.4 \pm 10.4$ & $8.11 \pm 1.43$ & $8.26 \pm 1.6$ \\
\hline Plateau pressure $\left(\mathrm{cmH}_{2} \mathrm{O}\right)$ & $25.3 \pm 5.09$ & $25.3 \pm 5.79$ & $23.7 \pm 5.85$ & $22.1 \pm 6.45$ & $16.77 \pm 7.32$ \\
$\mathrm{PEEP}(\mathrm{cm} \mathrm{H} \mathrm{O})$ & $7.20 \pm 3.24$ & $6.78 \pm 2.22$ & $6.55 \pm 2.37$ & $7.22 \pm 2.92$ & $5.6 \pm 3.67$ \\
$\mathrm{~Pa} / \mathrm{Fi}(\mathrm{mmHg})$ & $130.33 \pm 52.3$ & $150.4 \pm 53.5$ & $152.3 \pm 70.06$ & $144.6 \pm 47.5$ & $206.6 \pm 89.6$ \\
$\mathrm{pH}$ & $7.22 \pm 0.75$ & $7.37 \pm 0.31$ & $7.40 \pm 0.13$ & $7.43 \pm 0.07$ & $7.40 \pm 0.13$ \\
$\mathrm{PaCO}(\mathrm{mmHg})$ & $48.67 \pm 18.7$ & $46.9 \pm 17.96$ & $44.2 \pm 14.74$ & $44.16 \pm 12.61$ & $41.5 \pm 16.63$ \\
\hline Serum lactate $(\mathrm{mmol} / \mathrm{L})$ & $2.10 \pm 3.41$ & $1.29 \pm 0.93$ & $1.36 \pm 1.26$ & $1.17 \pm 1.26$ & $1.59 \pm 1.67$ \\
\hline Hemoglobin $(\mathrm{g} / \mathrm{dll})$ & $10.40 \pm 1.89$ & $10.07 \pm 1.50$ & $10.46 \pm 1.39$ & $10.26 \pm 1.60$ & $10.58 \pm 1.72$ \\
\hline
\end{tabular}

TABLE 2: Ventilatory gas exchange variables throughout the study.

Values are presented in mean \pm SD

PaCO2: Partial Pressure of Carbon dioxide, PEEP: Positive End-Expiratory Pressure, Pa/Fi: Relation between blood pressure and the fraction of inspired oxygen

The mean length of mechanical ventilation was $11.4 \pm 8.2$ days, and 39 patients $(44.8 \%)$ were extubated during the first week of ARDS. The median length of stay in PICU was 15 (10-23) days.

The mortality rate with ARDS varies based on severity. We found that patients at diagnosis with mild, moderate, and severe ARDS had mortality rates of $11 \%, 21.7 \%$, and $18.8 \%$, respectively (Figure 2 ).

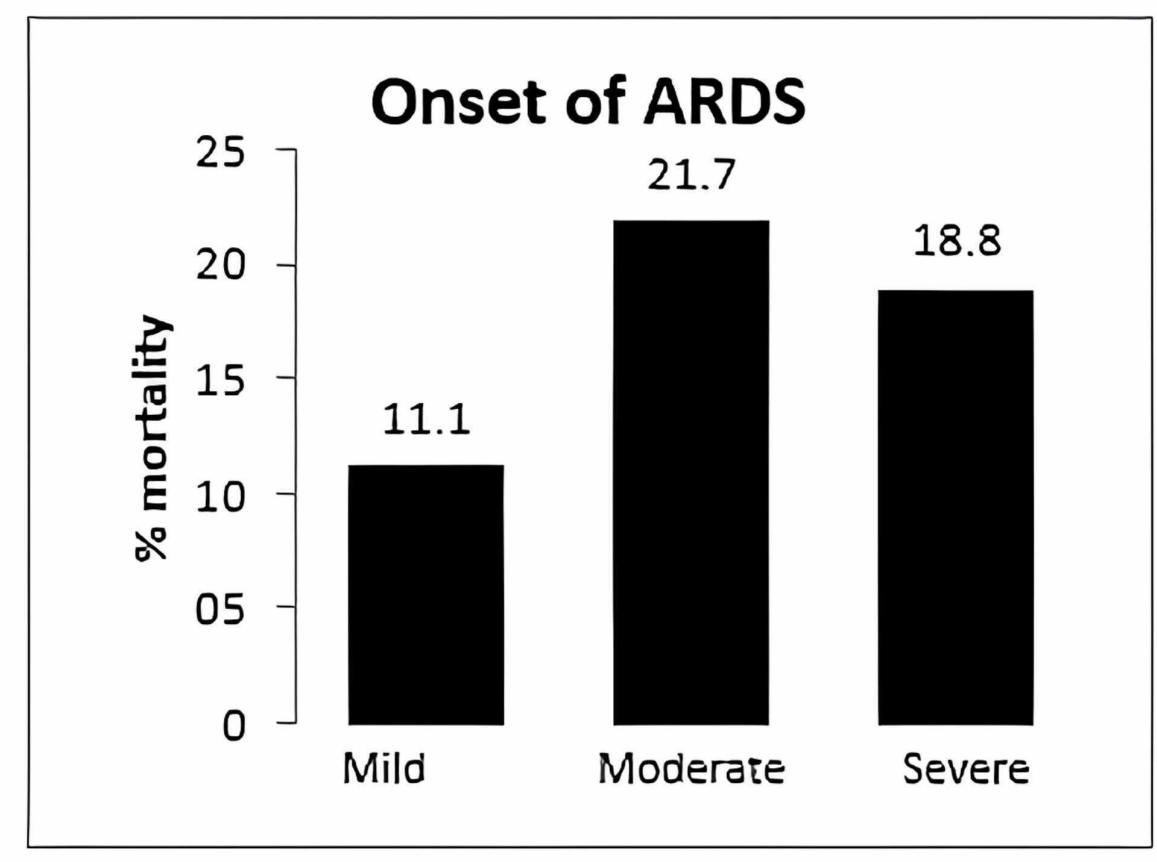

FIGURE 2: Mortality rate according to ARDS severity at diagnosis (based on the $\mathrm{Pa} / \mathrm{Fi}$ ratio).

ARDS: Acute Respiratory Distress Syndrome, Pa/Fi: Relation between blood pressure and the fraction of inspired oxygen

However, the mortality rates changed 24 hours later - patients with mild, moderate, and severe ARDS had 


\section{Cureus}

mortality rates of $25 \%, 11.9 \%$, and $46.7 \%$, respectively (Figure 3).

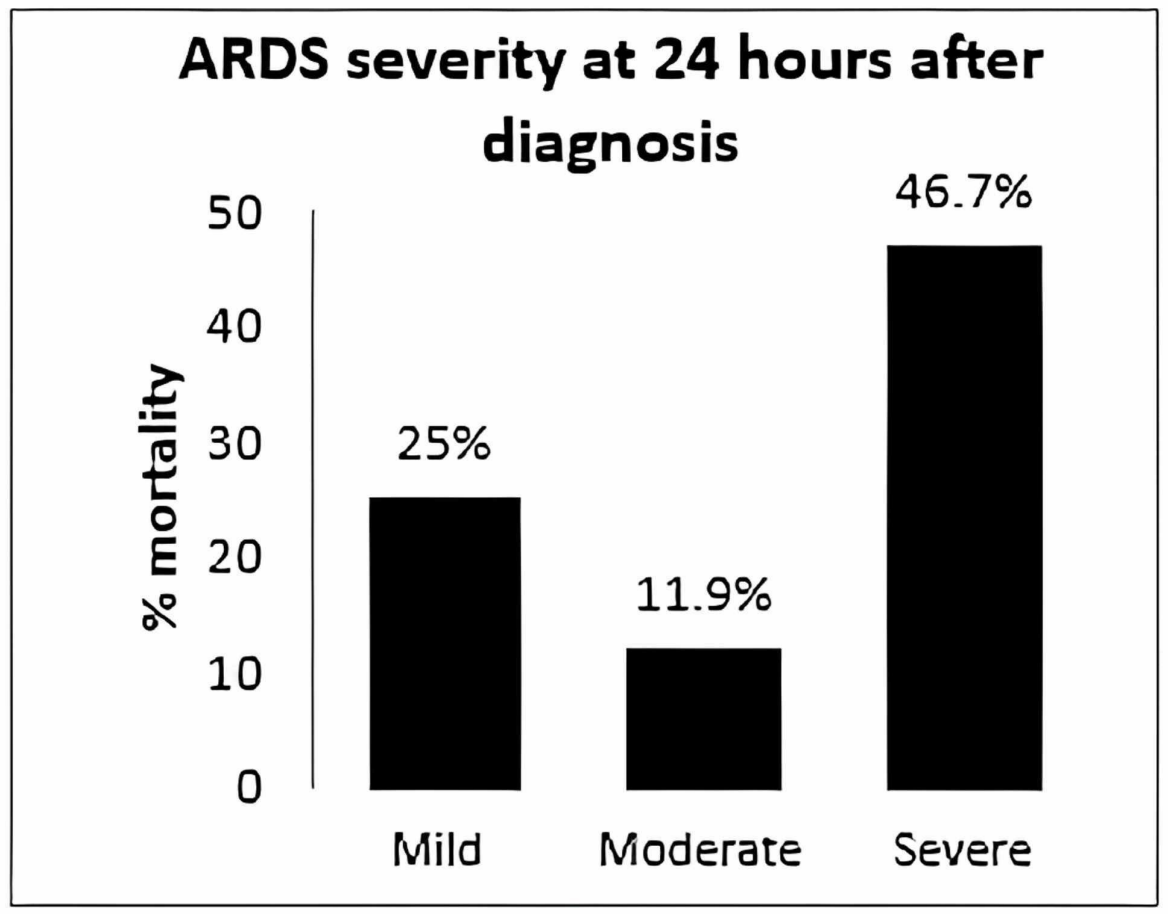

FIGURE 3: Mortality rate according to ARDS severity at 24 hours after diagnosis (based on the $\mathrm{Pa} / \mathrm{Fi}$ ratio).

ARDS: Acute Respiratory Distress Syndrome, Pa/Fi: Relation between blood pressure and the fraction of inspired oxygen

Another critical consideration in this context was the relation between serum lactate, tidal volume, PEEP, and mortality, at 24 hours of diagnosis of ARDS and the last day of mechanical ventilation (Table 3).

\begin{tabular}{|c|c|c|c|c|c|c|c|}
\hline & \multicolumn{3}{|c|}{ Patients who did not die } & \multicolumn{3}{|c|}{ Patiens who died } & \multirow{2}{*}{$P$ value } \\
\hline & P50 & P25 & P75 & P50 & P25 & P75 & \\
\hline PEEP24 & 6 & 5 & 8 & 9 & 6 & 10 & 0.0136 \\
\hline TV24 & 7.65 & 6.8 & 9.075 & 7.55 & 6.85 & 8.15 & 0.5906 \\
\hline LAC24 & 0.98 & 0.7 & 1.4 & 1.5 & 0.97 & 2.3 & 0.0026 \\
\hline PEEPLD & 5 & 4 & 5 & 7 & 5 & 12 & 0.001 \\
\hline TVLD & 8.1 & 7 & 9.575 & 7 & 6.9 & 7.6 & 0.0034 \\
\hline LACLD & 1 & 0.8 & 1.325 & 2.35 & 1.41 & 4.1 & 0.0009 \\
\hline
\end{tabular}

TABLE 3: PEEP values, tidal volume and serum lactate at 24 hours of diagnosis and the last day of mechanical ventilation.

PEEP24: Positive End-Expiratory Pressure at 24 hours; TV 24: Tidal volume at 24 hours; LAC 24: lactate at 24 hours; PEEPLD: PEEP the last day of mechanical ventilation; TVLD: Tidal volume the last day of mechanical ventilation; LACLD: lactate the last day of mechanical ventilation. P25: 25th percentile; P50: 50th percentile; p75: 75th percentile. 
higher in patients who died than those who survived. We found a significant difference in PEEP and serum lactate at 24 hours ( $p=0.013$ vs. 0.002 ) and a significant difference in PEEP and serum lactate the last day of mechanical ventilation ( $\mathrm{p}=0.001$ vs. 0.009 ). The present study did not find a significant difference in tidal volume at 24 hours.

Concerning the number of organs involved, as the number of involved organs increases, the mortality increases, and kidney dysfunction plays a critical role and is associated with an increased risk for mortality (Figure 4).

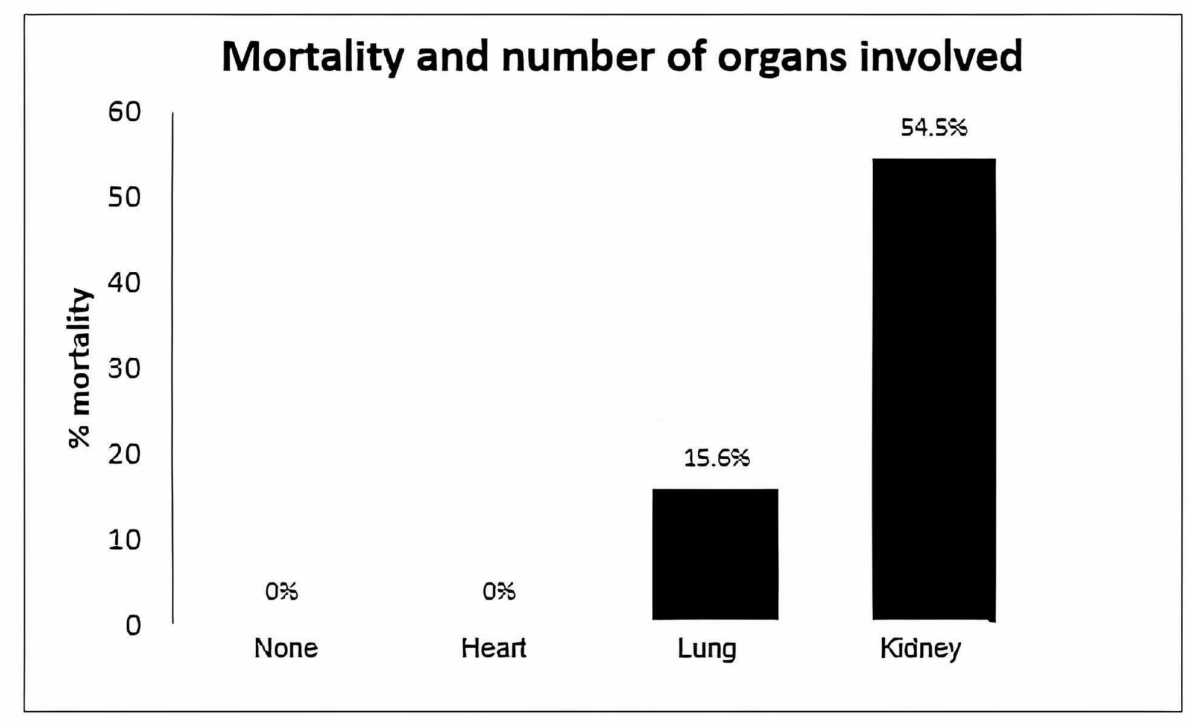

FIGURE 4: Mortality (\%) and number of organs involved.

\section{Discussion}

The present study is one of the first descriptions of the epidemiology and clinical course of ARDS in pediatric patients at moderate altitude. Reduced oxygen availability on lung physiology is the development of compensatory mechanisms and is an excellent area of academic research interest $[7,8,9]$. When we used a lung-protective ventilation strategy that has been standardized and studied in pediatric and adult population living at a lower altitude, we did not know the impact in children living at moderate altitudes and diagnosed with ARDS, however, this may affect the clinical course due to the different physiological baseline.

That was the main reason why the research was done in a university hospital of reference. In the present study the leading cause of ARDS was pneumonia (78.1\%), followed by bronchiolitis (9\%) and sepsis (8\%) which is consistent with previous reports in the literature, such as Flori et al. [11], with 328 patients reporting pneumonia as the primary underlying etiology of ARDS in 35\% of the cases, followed by aspiration pneumonia and sepsis. In a series of 146 patients in 2012, Lopez et al. [5] confirmed pneumonia as the most common lung condition leading to ARDS.

According to the Pediatric Acute Lung Injury Consensus Conference published in 2015, mechanical ventilation in patients with ARDS should be protective, using tidal volumes between 6 and $8 \mathrm{cc} / \mathrm{kg}$, a maximum plateau pressure of $32 \mathrm{cmH}_{2} \mathrm{O}$, and PEEP could be increased up to $10-15 \mathrm{cmH}_{2} \mathrm{O}$ according to the patient requirements [12].

In our study, these variables were analyzed at admission, 24 hours, day three, day seven, and the last day of mechanical ventilation. We found that the mean of plateau pressure was less than $25.3 \mathrm{cmH}_{2} \mathrm{O}$, and tidal volume varied between $7.9 \mathrm{ml} / \mathrm{kg}$ and $10.4 \mathrm{ml} / \mathrm{kg}$ throughout the study. $\mathrm{PEEP}$ was $7.2 \mathrm{cmH}_{2} \mathrm{O} \pm 3.2 \mathrm{cmH}_{2} \mathrm{O}$; the median was maintained between $6 \mathrm{cmH}_{2} \mathrm{O}$ and $6.5 \mathrm{cmH}_{2} \mathrm{O}$.

With these clinical findings, the correlation between PEEP, tidal volume, and mortality in the first 24 hours, and the last day of mechanical ventilation was estimated. The patients who died had a higher PEEP at 24 hours and the last day of mechanical ventilation ( $p=0.013$ vs. 0.002 ), while for the tidal volume, there was no significant difference at 24 hours $(\mathrm{p}=0.5$ ) (Table 3). These findings are consistent with the meta-analysis by Petrucci et al. [13], which included six studies performed in adults (1,297 patients) who received mechanical ventilation. The ventilatory strategies were compared, and the first one used a tidal volume of 7 $\mathrm{ml} / \mathrm{kg}$ or less and a plateau pressure of $30 \mathrm{cmH}_{2} \mathrm{O}$ or less versus ventilation with tidal volumes between 10 
and $15 \mathrm{ml} / \mathrm{kg}$. They reported more significant mortality at 28 days in patients with higher tidal volumes.

The subgroup analysis established that low or intermediate volumes $(8-10 \mathrm{ml} / \mathrm{kg})$ could be used if the plateau pressure is not greater than $31 \mathrm{cmH}_{2} \mathrm{O}$, which no affect the mortality rate. In the present study, we used intermediate tidal volume and low plateau pressure below $31 \mathrm{cmH}_{2} \mathrm{O}$, and it was not correlated with mortality.

These findings have been corroborated in pediatric patients in a meta-analysis and systematic review about tidal volume and mortality in ventilated pediatric patients [14,15], which did not find a relation between tidal volume and mortality. Previous investigations have shown that the overall mortality rate in pediatric ARDS ranges between $35 \%$ to $40 \%[5,11,13]$.

The severity of ARDS correlates with mortality; however, the $\mathrm{Pa} / \mathrm{Fi}$ ratio's clinical relevance as a marker of death was not clear. Yehya et al. [14], in a prospective study, determined that the measurement of $\mathrm{Pa} / \mathrm{Fi}$ at diagnosis was inaccurate because many patients had been reanimated improperly, and this could affect the measurement; at 24 hours the result was much more accurate, and it correlated with mortality. In our study, at diagnosis, the mortality rate was higher in the group with moderate ARDS than in the group with severe ARDS (21.7\% vs. 18.8\%), however, 24 hours later, the relation was reversed (11.9\% vs. $46.7 \%)$.

In 2012 Lopez et al. [5], in a prospective multicenter study, established that mortality correlates with the severity within 24 hours based on the analysis of the $\mathrm{PaO}_{2} / \mathrm{FIO}_{2}$. The patients with severe ARDS patients had a mortality rate of $38.5 \%$, those with moderate ARDS $20 \%$, and those with mild ARDS $11 \%$. Barreira et al. in 2013 conducted a prospective multicenter study in Brazil about the epidemiology and outcomes of pediatric ARDS according to the Berlin definition, and the authors concluded that the group with severe ARDS was the only group with a significant difference in mortality $(11 \%$ vs. $3 \%, p=0.002)$ and days free of mechanical ventilation (five vs. 20 days, $\mathrm{p}=0.001$ ) versus the group with mild and moderate ARDS [15].

Our study findings are partially correlated, the mortality rate in patients with severe ARDS was $46.7 \%$ at 24 hours; however, the patients' group with mild ARDS had higher mortality than the moderated ARDS at 24 hours. This could be explained by the fact that $\mathrm{Pa} / \mathrm{Fi}$ can be modified by the ventilation parameters and the vasoactive drug support; in this way, the patients classified as moderate at diagnosis, 24 hours later were classified as mild, then on day three, day seven, and last day of mechanical ventilation the mild ARDS turns into a severe ARDS and dies. These findings make us believe that $\mathrm{Pa} / \mathrm{Fi}$ is not a good predictor of mortality, and there are more factors involved in the outcome.

Several independent research groups $[13,14,15,16]$ have shown that the number of involved organs increases linearly as higher ARDS severity increases. Our study is correlated with previously published findings. The heart and lung compromise did not increase the mortality rate in our study, but if there is also kidney compromise, the mortality increases up to $15 \%$ and increases up to $54.5 \%$ if there are more than four organs involved, including heart, lung, kidney and hematologic (Figure 4).

The main limitation of this study is that it is not possible to directly extrapolate our results about mortality to the entire pediatric population living at a moderate altitude above mean sea level because this study was conducted in one single medical institution.

\section{Conclusions}

This study shows that pediatric ARDS clinical behavior in patients at moderate altitudes is similar to those pediatric patients with ARDS at low altitudes.

All patients had the same lung-protective ventilation, and it was not necessary to increase the ventilator parameters. The goals of oxygenation and alveolar ventilation were achieved. Tidal volume is an independent variable for mortality, while serum lactate and PEEP are correlated with mortality. We also identified the $\mathrm{Pa} / \mathrm{Fi}$ as a poor predictor of mortality for patients with mild or moderate ARDS because $\mathrm{Pa} / \mathrm{Fi}$ can be modified by the ventilator parameters and vasoactive drug support, and it was not correlated with mortality at 24 hours. Further multicenter studies are needed to assess the current outcome.

\section{Additional Information \\ Disclosures}

Human subjects: Consent was obtained by all participants in this study. Ethics committee of Fundación Cardioinfantil Instituto de Cardiología issued approval 0. This observational retrospective case series was approved by the ethics committee of the Fundación Cardioinfantil Instituto de Cardiología. It was not necessary to sign informed consent by parents because no intervention was performed on patients, and data was collected from the medical history. Animal subjects: All authors have confirmed that this study did not involve animal subjects or tissue. Conflicts of interest: In compliance with the ICMJE uniform disclosure form, all authors declare the following: Payment/services info: All authors have declared that no financial 
support was received from any organization for the submitted work. Financial relationships: All authors have declared that they have no financial relationships at present or within the previous three years with any organizations that might have an interest in the submitted work. Other relationships: All authors have declared that there are no other relationships or activities that could appear to have influenced the submitted work.

\section{References}

1. Cheifetz I: Advances in monitoring and management of pediatric acute lung injury . Pediatr Clin N Am. 2013, 60:621-639. 10.1016/j.pcl.2013.02.015

2. Ashbaugh D, Bigelow D, Petty T, Levine B: Acute respiratory distress in adults . Lancet. 1967, 2:319-23. 10.1016/s0140-6736(67)90168-7

3. Bernard G, Artigas A, Brigham K, et al.: The American-European Consensus Conference on ARDS. Definitions, mechanisms, relevant outcomes, and clinical trial coordination. Am J Respir Crit Care Med. 1994, 149:818-24. 10.1164/ajrccm.149.3.7509706

4. Ranieri M, Rubenfeld G, Thompson T, et al.: Acute respiratory distress syndrome: the Berlin definition . JAMA. 2012, 307:2526-33. 10.1001/jama.2012.5669

5. Lopez Y, Martínez A, de la Oliva P, et al.: Pediatric acute lung injury epidemiology and natural history study: incidence and outcome of the acute respiratory distress syndrome in children. Crit Care Med. 2012, 40:125132. 10.1097/CCM.0b013e318260caa3

6. Scherrer U, Allemann Y, Jayet P, Rexhaj E, Sartori C: High altitude, a natural research laboratory for the study of cardiovascular physiology and pathophysiology. Prog Cardiovasc Dis. 2010, 52:451-455. 10.1016/j.pcad.2010.02.002

7. Bärtsch P, Gibbs J: Effect of altitude on the heart and the lungs . Circulation. 2007, 116:2191-2202. 10.1161/CIRCULATIONAHA.106.650796

8. Peñaloza D, Arias J: The heart and pulmonary circulation at high altitudes: healthy highlanders and chronic mountain sickness. Circulation. 2007, 115:1132-1146. 10.1161/CIRCULATIONAHA.106.624544

9. Naeije R: Physiological adaptation of the cardiovascular system to high altitude . Prog Cardiovasc Dis. 2010, 52:456-468. 10.1016/j.pcad.2010.03.004

10. Bergeron M, Bahr R, Bärtsch P, et al.: International Olympic Committee consensus statement on thermoregulatory and altitude challenges for high-level athletes. Br J Sports Med. 2012, 46:770-779. 10.1136/bjsports-2012-091296

11. Flori H, Glidden D, Rutherford G, Matthay M: Pediatric acute lung injury: prospective evaluation of risk factors associated with mortality. Am J Respir Crit Care Med. 2005, 171:995-1001. 10.1164/rccm.200404$5440 \mathrm{C}$

12. The Pediatric Acute Lung Injury Consensus Conference Group: Pediatric acute respiratory distress syndrome: consensus recommendations from the Pediatric Acute Lung Injury Consensus Conference. Pediatr Crit Care Med. 2015, 16:428-39. 10.1097/PCC.0000000000000350

13. Petrucci N, De Feo C: Lung protective ventilation strategy for the acute respiratory distress syndrome Cochrane Database Syst Rev. 2013, 28:3844. 10.1002/14651858.CD003844.pub4

14. Yehya N, Servaes S, Thomas N: Characterizing degree of lung injury in pediatric acute respiratory distress syndrome. Crit Care Med. 2015, 43:937-946. 10.1097/CCM.000000000000867

15. Barreira E, Munoz G, Cavalheiro P, et al.: Epidemiology and outcomes of acute respiratory distress syndrome in children according to the Berlin definition: a multicenter prospective study. Crit Care Med. 2015, 43:947953. 10.1097/CCM.0000000000000866

16. Erickson S, Schibler A, Numa A, et al.: Acute lung injury in pediatric intensive care in Australia and New Zealand: a prospective, multicenter, observational study. Pediatr Crit Care Med. 2007, 8:317-323. 10.1097/01.PCC.0000269408.64179.FF 